\title{
Guiana Dolphin Unusual Mortality Event and Link to Cetacean Morbillivirus, Brazil
}

\author{
Kátia R. Groch, Elitieri B. Santos-Neto, \\ Josué Díaz-Delgado, Joana M.P. Ikeda, \\ Rafael R. Carvalho, Raissa B. Oliveira, \\ Emi B. Guari, Tatiana L. Bisi, \\ Alexandre F. Azevedo, José Lailson-Brito, \\ José L. Catão-Dias
}

During November-December 2017, a mass die-off of Guiana dolphins (Sotalia guianensis) began in Rio de Janeiro, Brazil. Molecular and pathologic investigations on 20 animals indicated that cetacean morbillivirus played a major role. Our findings increase the knowledge on health and disease aspects of this endangered species.

$\mathrm{C}$ etacean morbillivirus (CeMV; family Paramyxoviridae) is a highly infectious pathogen responsible for numerous cetacean mass die-offs worldwide. Currently, there are 3 well-characterized strains (1), the porpoise morbillivirus, the dolphin morbillivirus, and the pilot whale morbillivirus, and 3 less-known strains, including the novel Guiana dolphin strain (GD)-CeMV, recently identified in a single specimen from Brazil (2). CeMV was detected in Ireland, England, and the Netherlands in 1988-1990 (3,4), when the porpoise morbillivirus strain was identified in a small number of stranded harbor porpoises (Phocoena phocoena). Since then, CeMV has been implicated as the causal agent of numerous outbreaks and also endemic, sporadic deaths involving multiple cetacean species throughout the North Sea, north Atlantic Ocean, Mediterranean Sea, Black Sea, Indian Ocean (Western Australia), and Pacific Ocean (Hawaii, Japan, and Australia) (1).

To date, no epizootics linked to CeMV causing the death of large numbers of marine mammals has been detected in the South Atlantic. A Guiana dolphin (Sotalia guianensis) stranded in Espírito Santo, Brazil, which tested positive for CeMV by reverse transcription PCR (RT-PCR) and immunohistochemistry, has been the only confirmed fatal case in South Atlantic cetaceans (2). We describe the results of pathologic and molecular investigations on 20

Author affiliations: Universidade de São Paulo, São Paulo,

Brazil (K.R. Groch, J. Díaz-Delgado, J.L. Catão-Dias);

Universidade do Estado do Rio de Janeiro, Rio de Janeiro, Brazil

(E.B. Santos-Neto, J.M.P. Ikeda, R.R. Carvalho, R.B. Oliveira,

E.B. Guari, T.L. Bisi, A.F. Azevedo, J. Lailson-Brito)

DOI: https://doi.org/10.3201/eid2407.180139 deceased Guiana dolphins in the onset of the ongoing unusual mortality event in Rio de Janeiro, Brazil.

\section{The Study}

During November-December 2017, a unusual mortality event involving 56 Guiana dolphins began in Ilha Grande Bay, Rio de Janeiro (Brazil; 23․ $4^{\prime} 45^{\prime \prime}-23^{\circ} 13^{\prime} 38^{\prime \prime} \mathrm{S}$, $\left.44^{\circ} 5^{\prime} 30^{\prime \prime}-44^{\circ} 22^{\prime} 28^{\prime \prime} \mathrm{W}\right)$. This area is a relatively well-preserved ecosystem, and Guiana dolphin population census size in this area was estimated at $\approx 900$ animals (5). Stranding occurrence for the same period in previous years ranged from 0 to 3 specimens. During this event, carcasses were recovered adrift or washed ashore. We performed necropsies on 20/56 (37.7\%) Guiana dolphins and recorded epidemiologic and biologic data (Table 1).

We collected representative tissue samples of major organs and fixed them in $10 \%$ neutral buffered formalin or froze them at $-80^{\circ} \mathrm{C}$. For PCR analysis, we extracted viral RNA from frozen lung, brain, spleen, liver, and kidney (Table 1) using Brazol Reagent (LGC Biotecnologia Ltda, São Paulo, Brazil), according to the manufacturer's instructions. We used random primers and M-MLV Reverse Transcription Kit (Invitrogen, Life Technologies, Carlsbad, CA, USA) to synthesize cDNA. We performed amplification using primers targeting highly conserved fragments of the phosphoprotein (P) gene (6) and RNA-dependent RNA polymerase protein coded by the L gene (primers RESMOR-HEN) as previously described $(2,7)$.

We detected CeMV genome in 15/20 (75\%) animals for the $\mathrm{P}$ gene and $6 / 6(100 \%)$ animals for the $\mathrm{L}$ gene. We sequenced amplified products and compared them with sequences of CeMV using blastn (http://blast.ncbi.nlm.nih. gov/Blast.cgi). We obtained identical sequences for the $\mathrm{L}$ gene, and 2 sequences with variation in 1 nucleotide position for the P gene. Sequencing of 405-bp amplified fragments of the CeMV P gene revealed $99 \%-100 \%$ identity to GD-CeMV (2) and 78\%-82\% identity with other CeMV strains. A 443-bp amplified fragment of the CeMV L gene revealed $74 \%-75 \%$ identity to CeMV and other morbillivirus species. Partial $\mathrm{P}$ and $\mathrm{L}$ gene sequencing and analysis using MEGA7 (http://megasoftware.net/) corroborate that the GD-CeMV strain differed from other morbilliviruses and represented a distinct lineage (Figure 1).

For histologic examination, we embedded formalinfixed tissues in paraffin wax, processed them as routine, 
Table 1. Individual epidemiologic stranding data and biologic data of 20 Guiana dolphins stranded or retrieved from Ilha Grande Bay, Rio de Janeiro, Brazil, November 2017*

\begin{tabular}{|c|c|c|c|c|c|c|c|c|c|}
\hline No. & $\begin{array}{l}\text { Date } \\
\text { found }\end{array}$ & $\begin{array}{l}\text { Location } \\
\text { coordinates }\end{array}$ & Sex & $\begin{array}{l}\text { Body } \\
\text { length, } \\
\mathrm{cm}\end{array}$ & $\begin{array}{l}\text { Age } \\
\text { class }\end{array}$ & $\begin{array}{l}\text { Body } \\
\text { condition }\end{array}$ & $\begin{array}{l}\text { Decomp } \\
\text { status }\end{array}$ & Main gross findings & $\begin{array}{l}\text { CeMV RT- } \\
\text { PCR, } \\
\text { tissue/result }\end{array}$ \\
\hline 1 & 9 & $\begin{array}{l}-23.16738 \\
-44.13948\end{array}$ & $\mathrm{~F}$ & 177 & Adult & Poor & $\mathrm{Fr}$ & $\begin{array}{l}\text { Lactation; verminous pneumonia; } \\
\text { pulmonary edema; mediastinal } \\
\text { empyema; gastrointestinal petechiae, } \\
\text { gastrointestinal parasitosis; absence of }\end{array}$ & $\begin{array}{l}\text { Lung/pos, } \uparrow \\
\text { brain/pos, } \\
\text { spleen/pos }\end{array}$ \\
\hline
\end{tabular}

\begin{tabular}{|c|c|c|c|c|c|c|c|c|c|}
\hline & & & & & & & & Ingesta & \\
\hline 2 & 14 & $\begin{array}{l}-23.01327 \\
-44.44241\end{array}$ & $\mathrm{M}$ & 94 & Calf & Moderate & $\mathrm{Fr}$ & $\begin{array}{l}\text { Cyanotic mucous membranes; } \\
\text { pulmonary edema; hepatic lipidosis; } \\
\text { gastrointestinal petechiae }\end{array}$ & $\begin{array}{l}\text { Lung/pos, } † \\
\text { liver/pos }\end{array}$ \\
\hline 3 & 14 & $\begin{array}{l}-23.15123 \\
-44.32286\end{array}$ & $\mathrm{~F}$ & 124 & Juvenile & Poor & MA & $\begin{array}{l}\text { Pulmonary edema; gastric ulcers; } \\
\text { absence of ingesta }\end{array}$ & $\begin{array}{l}\text { Lung/pos, } \uparrow \\
\text { liver/pos }\end{array}$ \\
\hline 4 & 23 & $\begin{array}{l}-23.0319 \\
-44.54259\end{array}$ & ND & 71.5 & Calf & ND & AA & ND (AA) & Lung/pos† \\
\hline 5 & 23 & $\begin{array}{l}-23.03725 \\
-44.55784\end{array}$ & ND & 189 & Adult & ND & AA & Verminous pneumonia & $\begin{array}{l}\text { Lung/pos, } \uparrow \\
\text { liver/pos }\end{array}$ \\
\hline 6 & 23 & $\begin{array}{l}-23.08996 \\
-44.35695\end{array}$ & M & 160 & Juvenile & Poor & MA & $\begin{array}{l}\text { Verminous pneumonia; pulmonary } \\
\text { edema; absence of ingesta }\end{array}$ & $\begin{array}{l}\text { Lung/pos, } \uparrow \\
\text { brain/pos, } \\
\text { spleen/pos }\end{array}$ \\
\hline 7 & 24 & $\begin{array}{l}-23.00963, \\
-44.35695\end{array}$ & ND & 170 & ND & ND & AA & ND (AA) & Kidney/pos† \\
\hline 8 & 24 & $\begin{array}{l}-22.07896, \\
-44.23156 \\
\end{array}$ & ND & 132 & Juvenile & ND & AA & Black stained ingesta (plastic) & $\begin{array}{l}\text { Liver/neg, } \\
\text { spleen/neg }\end{array}$ \\
\hline 9 & 26 & $\begin{array}{l}-23.03688, \\
-44.55140\end{array}$ & M & 167 & Juvenile & ND & AA & ND (AA) & Kidney/neg \\
\hline 10 & 25 & $\begin{array}{l}-23.04786 \\
-44.57191\end{array}$ & M & 123 & Juvenile & Good & MA & $\begin{array}{l}\text { Proliferative pleuritis and peritonitis; } \\
\text { gastrointestinal parasitosis; absence of } \\
\text { ingesta }\end{array}$ & $\begin{array}{l}\text { Lung/pos, } \uparrow \\
\text { brain/pos, } \\
\text { spleen/pos }\end{array}$ \\
\hline 11 & 25 & $\begin{array}{l}-23.03637 \\
-44.55041\end{array}$ & $\mathrm{~F}$ & 123 & Juvenile & ND & AA & ND (AA) & $\begin{array}{l}\text { Lung/pos, } \dagger \\
\text { brain/pos, } \\
\text { spleen/pos }\end{array}$ \\
\hline 12 & 27 & $\begin{array}{l}-23.01980 \\
-44.44088\end{array}$ & $\mathrm{~F}$ & 124 & Juvenile & ND & MA & ND (AA); absence of ingesta & $\begin{array}{l}\text { Lung/pos, } \uparrow \\
\text { brain/pos, } \\
\text { spleen/pos }\end{array}$ \\
\hline 13 & 27 & $\begin{array}{l}-23.04542 \\
-44.59536\end{array}$ & $\mathrm{~F}$ & 142 & Juvenile & ND & AA & $\begin{array}{l}\text { Verminous pneumonia; gastrointestinal } \\
\text { parasitosis; absence of ingesta }\end{array}$ & $\begin{array}{l}\text { Lung/pos, } \\
\text { brain/post }\end{array}$ \\
\hline 14 & 28 & $\begin{array}{l}-23.16538 \\
-44.63874\end{array}$ & M & 118 & Juvenile & ND & AA & ND (AA); absence of ingesta & $\begin{array}{l}\text { Lung/pos, } \\
\text { brain/pos, } \\
\text { spleen/post }\end{array}$ \\
\hline 15 & 28 & $\begin{array}{l}-23.1325 \\
-44.62048\end{array}$ & $F$ & 182 & Adult & ND & AA & $\begin{array}{l}\text { Hydrothorax and ascites; verminous } \\
\text { pneumonia; absence of ingesta }\end{array}$ & $\begin{array}{l}\text { Lung/pos, } \uparrow \\
\text { brain/pos, } \\
\text { spleen/pos }\end{array}$ \\
\hline 16 & 28 & $\begin{array}{l}-23.12665 \\
-44.622 \\
\end{array}$ & M & 89 & Calf & ND & AA & Autolysis; absence of ingesta & $\begin{array}{l}\text { Lung/neg, } \\
\text { spleen/ neg }\end{array}$ \\
\hline 17 & 29 & $\begin{array}{l}-23.11585 \\
-44.66409\end{array}$ & $\mathrm{~F}$ & 170 & Adult & ND & MA & Pulmonary edema; absence of ingesta & $\begin{array}{l}\text { Lung/pos, } † \\
\text { spleen/pos }\end{array}$ \\
\hline 18 & 29 & $\begin{array}{l}-23.12927 \\
-44.66989\end{array}$ & M & 156 & Juvenile & Moderate & $\mathrm{Fr}$ & $\begin{array}{l}\text { Fishing gear lesions; hydrothorax and } \\
\text { ascites; verminous pneumonia; } \\
\text { pulmonary edema; hemopericardium; } \\
\text { gastroenteritis; gastrointestinal } \\
\text { parasitosis; urinary bladder petechiae; } \\
\text { pterygoid and tympanic bullae } \\
\text { trematodiasis }\end{array}$ & $\begin{array}{l}\text { Lung/neg, } \\
\text { spleen/neg }\end{array}$ \\
\hline 19 & 29 & $\begin{array}{l}-23.12726 \\
-44.67302\end{array}$ & $\mathrm{~F}$ & 144 & Juvenile & Good & $\mathrm{Fr}$ & $\begin{array}{l}\text { Fishing gear lesions; hydrothorax and } \\
\text { ascites; verminous pneumonia; } \\
\text { pulmonary edema; gastric ulcer; } \\
\text { gastrointestinal petechiae }\end{array}$ & $\begin{array}{l}\text { Lung/neg, } \\
\text { spleen/neg }\end{array}$ \\
\hline 20 & 30 & $\begin{array}{l}-23.07919, \\
-44.55559\end{array}$ & M & 125 & Juvenile & ND & AA & ND (AA); absence of ingesta & $\begin{array}{l}\text { Lung/pos, } \uparrow \\
\text { brain/pos }\end{array}$ \\
\hline
\end{tabular}

*Collection period was November 9-December 29, 2017. AA, advanced autolysis; decomp, decomposition; Fr, fresh; MA, moderate autolysis; ND, not determined; neg, negative; no., animal no.; pos, positive; RT-PCR, reverse transcription PCR.

†Amplified fragment sequenced. 


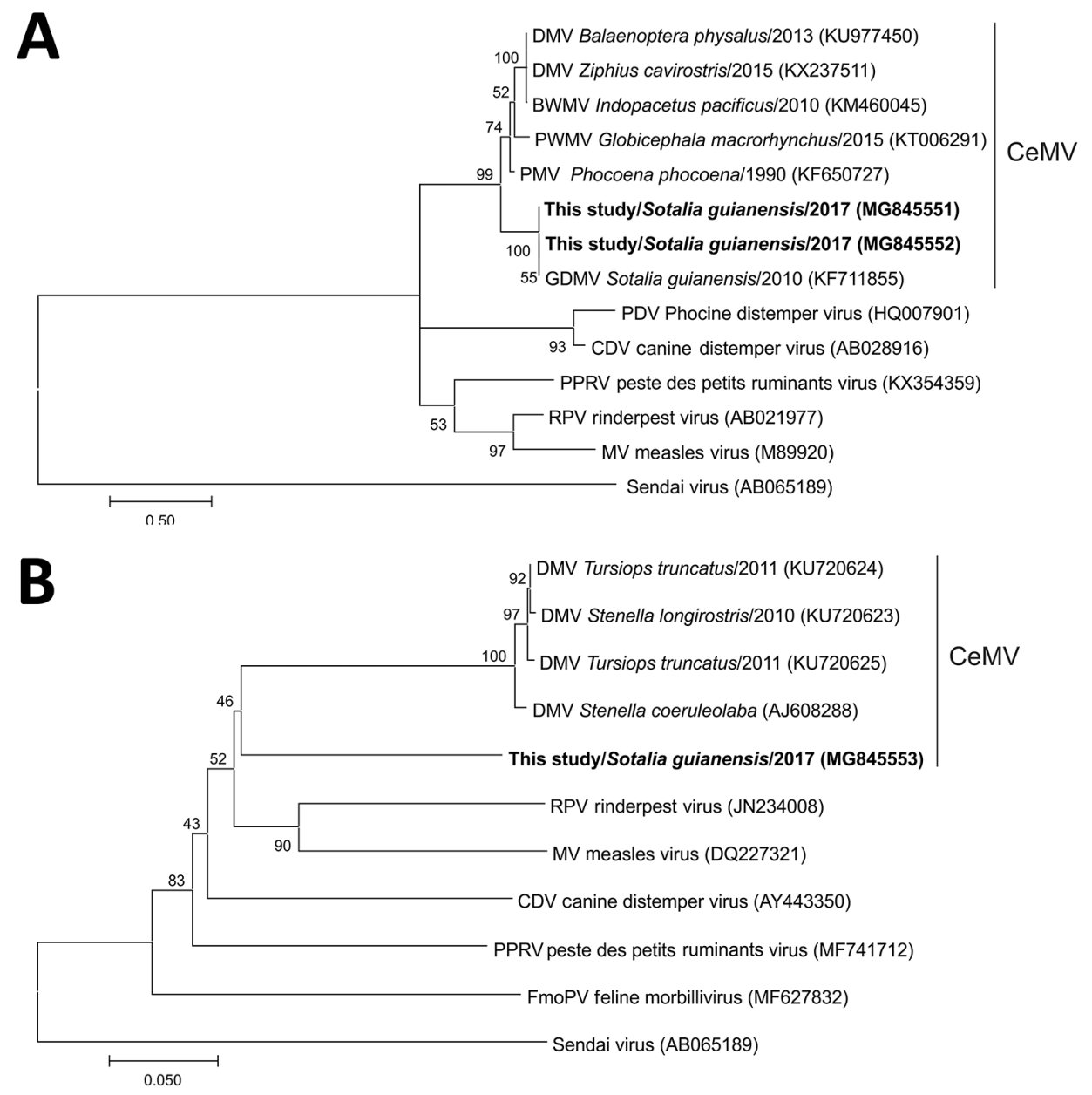

Figure 1. Phylogenetic tree showing partial sequence of A) morbillivirus phosphoprotein and B) large protein genes of cetacean morbillivirus (CeMV) isolates found in stranded Guiana dolphins (Sotalia guianensis) from Rio de Janeiro, Brazil (bold), 2017, and those of other previously described morbilliviruses. Sendai virus was added as an outgroup. Trees were generated by the maximum-likelihood method (A) and neighbor-joining method (B); bootstrap values $(1,000$ replicates) are indicated at the internal nodes. For comparison, recognized CeMV strains were included when available. Sequence names are followed by species, year of stranding (when available), and GenBank accession number. Scale bars indicate nucleotide substitutions per site. PMV, porpoise morbillivirus; DMV, dolphin morbillivirus; BWMV, beaked whale morbillivirus; PWMV, pilot whale morbillivirus.

and stained them with hematoxylin and eosin. We recorded detailed histopathologic findings of 6 animals positive for CeMV by RT-PCR (Table 2). One specimen had lesions consistent with CeMV infection, including marked multifocal, subacute bronchointerstitial pneumonia with type II pneumocyte hyperplasia, syncytia, and scattered intraepithelial, intranuclear, and intracytoplasmic inclusion bodies (INCIBs); mild to moderate multifocal histiocytic and lymphoplasmacytic mastitis with necrosis and epithelial INCIBs (Figure 2, panels A-C); and multicentric lymphoid depletion. In addition, most animals had moderate to severe verminous bronchopneumonia and pleuritis with morphologic evidence of pulmonary arterial hypertension, multicentric eosinophilic and necrotizing lymphadenitis, and chronic aortic endarteritis by adult nematodes and pulmonary endarteritis by migrating larval nematodes histomorphologically compatible with Halocercus brasiliensis (8). Other common findings included moderate to poor body condition and lack of ingesta with small amounts of feces. Two (10\%) of the 20 animals (which were negative for CeMV by RT-PCR) showed typical external net markings and multiorgan acute hemodynamic alterations (congestion, edema, and hemorrhage) supporting asphyxia due to bycatch as the cause of death.

We performed immunohistochemistry studies using a monoclonal antibody against the nucleoprotein antigen of canine distemper virus (CDV-NP mAb; VMRD Inc., Pullman, WA, USA), as described (2). In lung tissue sections (cases 1, 2, 11, and 13), we evaluated number and distribution of immunopositive cells and immunolabeling intensity. Lung samples from all animals tested showed widespread and intense immunolabeling in bronchial, bronchiolar, and alveolar epithelium, alveolar macrophages, and syncytia (Figure 2, panels D,E).

In this investigation, typical histopathologic findings consistent with CeMV were evident in 1 animal, indicating a systemic infection. Although chronic bronchointerstitial pneumonia and multicentric lymphoid depletion observed in most animals are common findings in CeMV-infected cetaceans, these lesions were considerably overlapped by $H$. brasiliensis endoparasitosis. The pathologic signatures of GD-CeMV remain unknown. No other CeMV strain has been described in the South Atlantic Ocean. In subacute and chronic CeMV presentations, fatalities are often ascribed 
Table 2. Summary of histopathologic findings for 6 Guiana dolphins recovered from Ilha Grande Bay, Rio de Janeiro, Brazil, 2017*

\begin{tabular}{lll}
\hline No. & Tissue \\
\hline $1 \dagger$ & Lung
\end{tabular}

Mammary gland

Heart

Kidney

Pulmonary lymph node

Mediastinal lymph node

Spleen

Adrenal

Aorta

Liver

Uterus

Glandular stomach

$2 \ddagger \quad$ Lung

Kidney

Pulmonary lymph node

Prescapular lymph node

\begin{tabular}{cc} 
& Spleen \\
& Heart \\
& Adrenal \\
& Esophagus \\
& Urinary bladder \\
& Penis \\
& Cerebrum, cerebellum \\
& Lung \\
\hline $10 \S$ & Keratinized stomach \\
& Skeletal muscle \\
& Ascending aorta
\end{tabular}

Aortic (semilunar) valve

\begin{tabular}{lc} 
& Aortic (semilunar) valve \\
\hline $12 \pi$ & Keratinized stomach \\
\hline $13 \#$ & Lung
\end{tabular}

Skin

Pyloric stomach
Histopathologic findings

Marked, multifocal chronic bronchointerstitial pneumonia and proliferative pleuritis with sclerosis, type II pneumocyte hyperplasia, syncytia/multinucleated cells, rare INCIBs, calcified nematode debris and edema; multifocal tunica media hypertrophy/hyperplasia Mild to moderate, multifocal, chronic lymphoplasmacytic and histiocytic mastitis with acinar ectasia, inspissated secretion, scattered necrosis, ceroid pigment and moderate INCIBs in epithelium

Mild, focal, subacute fibrinous pericarditis; mild, multifocal myocardial fibrosis Mild, multifocal, chronic membranous glomerulonephritis with glomerulocysts, tubular proteinosis, protein casts, and scattered tubuloepithelial necrosis

Mild, multifocal, chronic nodular eosinophilic and necrotizing lymphadenitis with fibrosis and hemosiderosis; diffuse lymphoid depletion

Mild, multifocal, chronic eosinophilic lymphadenitis; diffuse congestion

Diffuse congestion and multifocal, acute capsular hemorrhage; extramedullary hematopoiesis Mild, multifocal, acute corticomedullary hemorrhage Mild, segmental, chronic proliferative endarteritis

Moderate, multifocal, chronic bile duct adenomatous hyperplasia

Moderate, multifocal, chronic arteriosclerosis and arterial elastosis

Mild, diffuse mucosal hyperplasia; multifocal arterial tunica media hypertrophy/hyperplasia

Mild, multifocal, acute interstitial pneumonia associated with marked alveolar edema, hemorrhage and alveolar histiocytosis, syncytia/multinucleated cells and keratin spicules Mild, multifocal, acute tubular degeneration and necrosis; mild, multifocal, acute tubular proteinosis and protein casts; marked, focal, acute perirenal hemorrhage

Moderate, diffuse cortical and paracortical lymphoid depletion with scattered lymphocytolysis

Diffuse congestion with focal acute hemorrhage and erythrophagocytosis; sinus vascularization

Moderate, diffuse, lymphoid depletion with sinus histiocytosis; extramedullary hematopoiesis Moderate, multifocal, acute subendocardial and epicardial hemorrhage Marked, multifocal, acute cortico-medullary hemorrhagic necrosis Focal acute hemorrhage in serosa

Edema and focal acute hemorrhage in serosa

Urethral luminal hemorrhage with single cell epithelial necrosis/apoptosis Diffuse leptomeningeal congestion and perivascular edema in neuroparenchyma

Mild to moderate, multifocal, chronic suppurative bronchopneumonia with adult nematodes

(Halocercus sp.); multifocal alveolar, bronchiolar and bronchial mineralization Mild, focal, chronic proliferative gastritis Scattered acute hyaline myocyte degeneration and necrosis

Marked, segmental, chronic fibrosing and proliferative endarteritis with chondroid metaplasia and calcification; moderate, focal, chronic granulomatous periarteritis; mild, multifocal intimal fibroelastosis

Mild, multifocal, chronic intimal/endocardial fibroelastosis Mild, focal, chronic mononuclear gastritis

Marked, multifocal, chronic suppurative to pyogranulomatous bronchopneumonia with bronchial/olar sclerosis, adult and larval nematodes (Halocercus sp.) and moderate, multifocal, chronic proliferative and fibrosing (villous) pleuritis; marked, multifocal, chronic tunica media arterial hypertrophy/hyperplasia with stenosis Mild, multifocal, chronic irregular epidermal hyperplasia

Moderate, focal, chronic granulomatous gastritis with numerous trematode ova (compatible with Pholeter gastrophilus)

*INCIBs, intranuclear and intracytoplasmic inclusion bodies; no., animal no.

†No significant lesions were observed for large intestine, thyroid, skin, trachea, cerebrum, cerebellum, spinal cord, or skeletal muscle.

$\ddagger$ No significant lesions were observed for keratinized and pyloric stomach, tongue, aorta, small intestine, pancreas, or trachea.

§Unable to observe lesions in liver, spleen, kidney, testicle, trachea, small and large intestine, skin, periaortic lymph node, cerebrum, or cerebellum

because of advanced autolysis of animal.

TUnable to observe lesions in ovary, skin, liver, skeletal muscle, heart, kidney, spleen, large intestine, bladder, lymph node, or adrenal gland because of advanced autolysis of animal.

\#Unable to observe lesions in small intestine, liver, skeletal muscle, adrenal gland, bladder, kidney, or heart because of advanced autolysis of animal.

to secondary infections (e.g., toxoplasmosis, aspergillosis) $(9,10)$. In our cohort, autolysis precluded microscopic examinations in some animals, so we could not draw further pathologic conclusions. Nonetheless, moderate to severe parasitosis by $H$. brasiliensis likely accounted for severe illness in most cases. Intense viral replication in the mammary acinar epithelium in a lactating female may imply a vertical transmission route, in addition to the horizontal aerogenous and direct contact routes (10). Therefore, future pathologic and epidemiologic studies in the South Atlantic should consider vertical transmission. Two cases from this cohort were bycaught, further supporting the multifactorial nature of the ongoing unusual mortality event.

The Guiana dolphin is a coastal and estuarine delphinid endemic from southern Brazil to Central America and one of the most threatened South Atlantic cetaceans, for which 

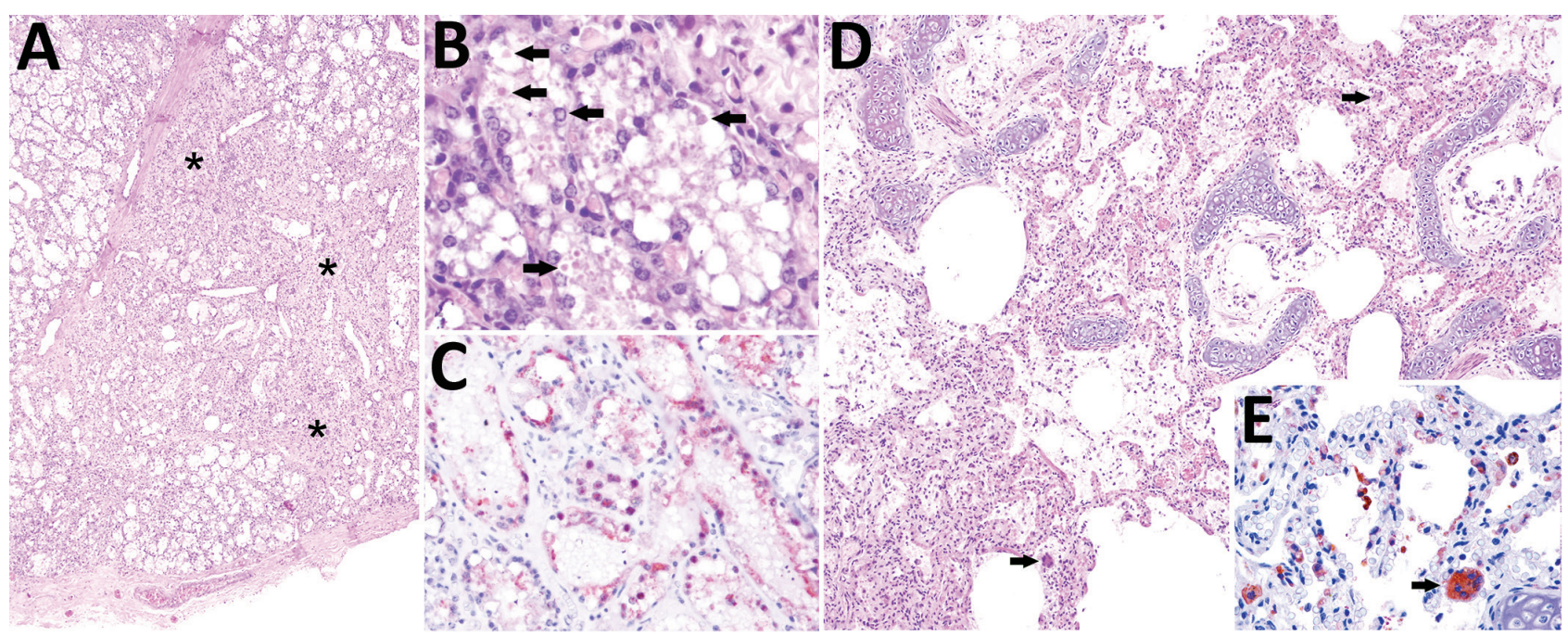

Figure 2. Cetacean morbillivirus-associated histopathologic findings in 2 Guiana dolphins (Sotalia guianensis), a female adult (case 1 , panels $A-C$ ) and a male calf (case 2, panels D-E). A) The mammary gland parenchyma is focally disrupted by lymphohistiocytic inflammatory cells (not visible at this magnification) associated with collapsed and lost acini, and mild fibrosis (asterisks). Original magnification $\times 40$; hematoxylin and eosin $(\mathrm{H} \& \mathrm{E})$ stain. B) Swollen and degenerating mammary acinar epithelial cells have numerous intracytoplasmic and intranuclear inclusion bodies (arrows). Original magnification $\times 200$; H\&E stain. C) Degenerating and sloughed mammary acinar epithelial cells have intense granular cytoplasmic and intranuclear immunolabeling, identified by immunohistochemistry (IHC) for canine distemper virus (CDV), known to cross react with cetacean morbilliviruses. D) Pulmonary area displaying interstitial pneumonia with mildly thickened alveolar septa and alveoli containing proteinaceous edema, scattered fibrin strands, and small numbers of pleocellular inflammatory cells including occasional syncytia (arrows). Original magnification $\times 100$; H\&E stain. E) Degenerating and necrotic type I pneumocytes, sloughed and adhered type II pneumocytes, alveolar and septal macrophages, syncytia (arrow) and circulating (intravascular) mononuclear cells display intense immunolabeling. Original magnification $\times 400$; IHC for CDV.

recent studies demonstrate severe population decline (11). Because of its near-shore distribution and site fidelity (12), the Guiana dolphin is susceptible to the effects of human activities (e.g., habitat degradation, chemical pollution, noise, and bycatch) (13). Many intricate and complex anthropic and natural factors interplay and modulate the decline of species. Human activities are by far the major threat and cause for decimation of cetacean populations (14); however, natural factors such as highly infectious pathogens, e.g., CeMV, may drive decimating events in susceptible hosts (15).

\section{Conclusions}

We provide compelling molecular and pathologic evidence associating GD-CeMV infection with the ongoing Guiana dolphin mass die-off near Rio de Janeiro, Brazil. As of January 2018, this event had resulted in the deaths of $>200$ Guiana dolphins in southern Rio de Janeiro state, and the deaths appeared to be extending southward. The environmental consequences and conservation effects, coupled with the anthropogenic threats, are expected to be dramatic. The factors underlying the die-off are being investigated, but our results indicate that GD-CeMV plays a major contributory role. Our findings increase the body of knowledge on health and disease aspects of this endangered species.

\section{Acknowledgments}

We thank the Laboratório de Mamíferos Aquáticos e Bioindicadores (MAQUA/UERJ) team for their assistance in stranding monitoring and necropsy procedures and Haydée A. Cunha for helpful comments on the draft of this manuscript.

Programa de Conservação dos botos-cinza (Sotalia guianensis) e outros cetáceos das baías da Ilha Grande e de Sepetiba (MAQUA/UERJ, Associação Cultural e de Pesquisa Noel Rosa, INEA, Transpetro) and Projeto de Monitoramento de Praias da Bacia de Santos (PMP-BS) (MAQUA/UERJ, CTA Meio Ambiente, Instituto Boto Cinza, Petrobras) support cetacean research in this region. PMP-BS is a monitoring program demanded by the federal environmental licensing conducted by IBAMA. This research was also supported by Coordination for the Improvement of Higher Education Personnel (CAPES) and São Paulo Research Foundation (FAPESP), grants \#2014/24932-2, \#2015/00735-6, and \#2017/02223-8. J.L.C.-D. is the recipient of a fellowship from the National Research Council (CNPq; grant \#305349/2015-5); A.F.A., J.L-B., and T.L.B. are funded by research grants from CNPq (PQ-1D, PQ-1C, and PQ-2, respectively), FAPERJ (CNE and JCNE, respectively), and UERJ (Prociência). 


\section{About the Author}

Dr. Groch is a postdoctoral fellow studying the advancement of pathology of cetaceans in Brazil, particularly of infectious diseases. Her current research focuses on determining geographic and host ranges for CeMV, as well as delineating the pathologic signature and CeMV strains present in cetaceans of Brazil.

\section{References}

1. Van Bressem M-F, Duignan PJ, Banyard A, Barbieri M, Colegrove KM, De Guise S, et al. Cetacean morbillivirus: current knowledge and future directions. Viruses. 2014;6:5145-81. http://dx.doi.org/10.3390/v6125145

2. Groch KR, Colosio AC, Marcondes MC, Zucca D, Díaz-Delgado J, Niemeyer C, et al. Novel cetacean morbillivirus in Guiana dolphin, Brazil. Emerg Infect Dis. 2014;20:511-3. http://dx.doi.org/10.3201/ eid2003.131557

3. Kennedy S, Smyth JA, Cush PF, McCullough SJ, Allan GM, McQuaid S. Viral distemper now found in porpoises. Nature. 1988;336:21. http://dx.doi.org/10.1038/336021a0

4. Visser IK, Van Bressem MF, de Swart RL, van de Bildt MW, Vos HW, van der Heijden RW, et al. Characterization of morbilliviruses isolated from dolphins and porpoises in Europe. J Gen Virol. 1993;74:631-41. http://dx.doi.org/10.1099/ 0022-1317-74-4-631

5. Souza SCP. Estimation of population parameters of the Guiana dolphin, Sotalia guianensis (Van Bénéden, 1864) (Cetacea, Delphinidae) in Paraty Bay (RJ). Rio de Janeiro (Brazil): Universidade do Estado do Rio de Janeiro; 2013.

6. Barrett T, Visser IKG, Mamaev L, Goatley L, van Bressem M-F, Osterhaus ADME. Dolphin and porpoise morbilliviruses are genetically distinct from phocine distemper virus. Virology. 1993;193:1010-2. http://dx.doi.org/10.1006/viro.1993.1217

7. Tong S, Chern SW, Li Y, Pallansch MA, Anderson LJ. Sensitive and broadly reactive reverse transcription-PCR assays to detect novel paramyxoviruses. J Clin Microbiol. 2008;46:2652-8. http://dx.doi.org/10.1128/JCM.00192-08
8. Delyamure SL. Helminthofauna of marine mammals (ecology and phylogeny) [translated from Russian]. Jerusalem: Israel Program for Scientific Translation Ltd.; 1968.

9. Stephens N, Duignan PJ, Wang J, Bingham J, Finn H, Bejder L, et al. Cetacean morbillivirus in coastal Indo-Pacific bottlenose dolphins, Western Australia. Emerg Infect Dis. 2014;20:666-70. http://dx.doi.org/10.3201/eid2004.131714

10. Domingo M, Visa J, Pumarola M, Marco AJ, Ferrer L, Rabanal R, et al. Pathologic and immunocytochemical studies of morbillivirus infection in striped dolphins (Stenella coeruleoalba). Vet Pathol. 1992;29:1-10. http://dx.doi.org/10.1177/030098589202900101

11. Azevedo AF, Carvalho RR, Kajin M, Van Sluys M, Bisi TL, Cunha HA, et al. The first confirmed decline of a delphinid population from Brazilian waters: 2000-2015 abundance of Sotalia guianensis in Guanabara Bay, South-eastern Brazil. Ecol Indic. 2017;79:1-10. http://dx.doi.org/10.1016/j.ecolind.2017.03.045

12. Flores PAC, Silva VMFD. Tucuxi and Guiana dolphin: Sotalia fluviatilis and S. guianensis. In: Perrin WF, Wursig B,

Thewissen JGM, editors. Encyclopedia of marine mammals, 2nd ed. San Diego (CA): Academic Press; 2009. p. 1188-92.

13. Crespo EA, Notarbartolo di Sciara G, Reeves RR, Smith BD Dolphins, whales, and porpoises: 2002-2010 conservation action plan for the world's cetaceans. Gland (Switzerland) and Cambridge: International Union for Conservation of Nature; 2003.

14. Ceballos G, Ehrlich PR, Barnosky AD, García A, Pringle RM, Palmer TM. Accelerated modern human-induced species losses: entering the sixth mass extinction. Sci Adv. 2015;1:e1400253. http://dx.doi.org/10.1126/sciadv.1400253

15. Forcada J, Aguilar A, Hammond PS, Pastor X, Aguilar R. Distribution and numbers of striped dolphins in the western Mediterranean Sea after the 1990 epizootic outbreak. Mar Mamm Sci. 1994;10:137-50. http://dx.doi.org/10.1111/j.1748-7692.1994. tb00256.x

Address for correspondence: Kátia R. Groch, Wildlife Comparative Pathology Laboratory, School of Veterinary Medicine and Animal Science, University of São Paulo, Av Prof. Orlando Marques de Paiva, 87 São Paulo, SP, 05508-270, Brazil; email: katia.groch@gmail.com

\title{
GOVDELIVERY
}

\section{Manage your email alerts so you only receive content of interest to you.}

\author{
Sign up for an online subscription: \\ wwwnc.cdc.gov/eid/subscribe.htm
}

